the first possibility would leave the United States with an "unhealthy" fusion research programme, but that the second is workable if the money is carefully spent.

The first thing the committee did, however, was to try to devise some way to save the burning plasma experiment, which is planned to succeed the Tokamak Fusion Test Reactor at Princeton University after work there is finished in two years. They concluded that the project would demand annual funding increases of 10 to 15 per cent and that stretching out its schedule would be impractical.

The major problem facing the US fusion community, Conn said, is that the removal of the burning plasma experiment leaves a gap between the finish of the tokamak experiment at Princeton and the beginning of the International Thermonuclear Experimental Reactor (ITER), during which time US scientists would not have enough to do to keep the research effort strong.

To fill the gap, the fusion advisory committee recommends that the DOE fund another major research effort, smaller in scope than the burning plasma experiment and inexpensive enough to fit into the confines of a fusion programme growing at five per cent a year. Ideally, such a programme would come on line three to five years before ITER and would offer operational experience for running ITER and also provide data that the later experiment is not designed to obtain.

Work on a proposal for the new project should be funded with part of the $\$ 27$ million already allocated in fiscal year 1992 for the burning plasma experiment, the committee recommends. After working with the US fusion community, the advisory committee should be able to offer one or more specific proposals by next August, in time to decide on funding for fiscal 1994, Conn said.

The loss of the burning plasma experiment will give ITER the major role in the US fusion programme and will also force a rethinking of how US researchers want to use ITER. Until now, US fusion scientists had generally expected the burning plasma experiment to provide much of the physical data necessary to plan a fusion reactor; in this case, ITER would be used more for testing technology than for doing basic science. Many European scientists, on the other hand, had hoped that ITER would concentrate more on physical experimentation. The Europeans, it now seems, will win this argument by default, as US researchers will have no place other than ITER to get their data.

The fusion advisory committee also recommended using some of the \$27 million to increase support for existing fusion programmes, many of which have not been operating at full capacity because of insufficient operating funds.

Robert Pool

\section{Soviet space gloom}

IN the next few weeks Soviet authorities are expected to cancel the Buran space shuttle project, which has seen only one launch, in 1988. Buran, which bears a striking resemblance to its US counterpart, is expected to be just one victim of wide-ranging cuts across the whole of the Soviet space programme, made necessary by the dire state of the country's economy. The centralized Soviet space programme is also threatened by the wish of individual republics - notably the Russian Federation and Kazakhstan, home to the main Soviet launch sites - to manage their own space programmes.

P.A.

\section{Marine cats' eyes}

ThE Moray Firth in Scotland last week played host to field trials of a simple device designed to reduce the number of dolphins and porpoises killed in drift fishing nets estimated by environmentalist groups to total $\mathbf{1 . 5}$ million a year. Researchers from Cambridge, Loughborough and Aberdeen universities hope that attaching sonar-reflective floats to fishing nets will increase their 'visibility' to feeding dolphins, and so prevent many from becoming entangled.

Margaret Klinowska, a Cambridge biologist, likens the reflective floats to the familiar 'cats' eyes' used to highlight road markings in the dark. The key to the success of the project, she says, is to make nets register on dolphins' sonar from a distance of 70-90 metres - the distance over which dolphins scan when searching for their fish prey. Conventional nets are detected by dolphins only once they are within 10 metres. Klinowska says that dolphins last week did seem to avoid a series of ropes spaced 2 metres apart each carrying reflective floats at 1-metre intervals, but it will take several weeks to analyse recordings of the dolphins' sonar pulses to discover whether the floats were detected.

P.A.

\section{Japanese firms opt out}

US PRESSURE on Japan to open up its satellite market to foreign (and in particular US) satellite manufacturers appears to have paid off. Last month, the huge domestic telecommunications company Nippon Telegraph and Telephone (NTT) announced that only US manufacturers submitted bids to supply a next-generation communication satellite to be launched for NTT in 1995.

Last year, during the US-Japan trade talks, Japan agreed under US pressure to open up its satellite market to foreign competition. Originally, the Japanese government had planned to build the NTT satellite as a national project led by the National Space Development Agency (NASDA), but this plan was dropped in the face of US criticism. Japanese satellite manufacturers say they did not submit bids because they do not have adequate facilities for testing the satellite and they could not use NASDA facilities for fear of US complaints that their manufacture of satellites is subsidized by the Japanese government.

David Swinbanks

\section{Animal supplier charged}

If the US Department of Agriculture (USDA) gets its way, the nation's largest supplier of animals for school dissection may soon feel the knife itself. In a complaint filed last week, USDA charged Carolina Biological Supply Company with embalming cats while they were still alive, improperly killing other animals and six other "wilful" violations of the Animal Welfare Act. USDA wants to fine the company and strip it of its licence. The charges stem from a 1990 investigation by undercover members of the animal-rights group People for the Ethical Treatment of Animals (PETA) who videotaped procedures at the company over seven days. In a statement released last week, Carolina Biological said that the cats were actually dead when they were embalmed, and were simply showing "involuntary, postmortem muscular movement". USDA has so far offered no evidence to the contrary, the company said, adding that it has taken steps to deal with USDA's other concerns.

C.A.

\section{Leukaemia favours rich}

Children from families of higher socioeconomic status are more likely to develop leukaemia than children from poorer families, according to a survey of almost 10,000 leukaemic children published last week by the UK Office of Population Censuses and Surveys. A University of Oxford team looked at cases over the whole of Britain diagnosed between 1966 and 1983, and correlated these with socioeconomic status at the level of county districts. Study leader Gerald Draper says the result confirms previous findings with smaller data sets, but the reasons for the link are still unclear. Draper speculates that the age at which children become exposed to viruses thought to trigger abnormal cell proliferation - likely to be later in children raised in more affluent families - may be an important factor.

Leukaemia epidemiology has been a controversial subject in Britain ever since clusters of childhood cases were identified around nuclear installations at Sellafield in Cumbria, Dounreay in Scotland, and Aldermaston and Burghfield in southern England. In the light of his results, Draper believes that the leukaemia cluster around the Aldermaston and Burghfield nuclear weapons research laboratories could be explained in part by the relative affluence of the surrounding area. 